\title{
SUPERAÇÃO IN VITRO DA DORMÊNCIA DE EMBRIÕES DO PORTA- ENXERTO DE MACIEIRA M9 (Malus pumilla Mill.) ${ }^{1}$
}

\author{
ADRIANA CIBELE DE MESQUITA DANTAS ${ }^{2}$, LIZIANE KADINE ANTUNES DE MORAES ${ }^{3}$, ENIO LUIZ \\ PEDROTTI $^{3}$, RUBENS ONOFRE NODARI ${ }^{4}$, MIGUEL PEDRO GUERRA ${ }^{4}$
}

\begin{abstract}
RESUMO - A dormência em sementes de macieira é um dos fatores limitantes para o avanço nos programas de melhoramento genético nesta espécie. Assim, o presente estudo objetivou estudar a germinação in vitro de embriões dormentes do porta-enxerto de macieira M9, oriundos da EE São Joaquim da EPAGRI/SC. Os embriões foram excisados de sementes maduras e inoculados em meio basal MS, adicionado de sacarose (30 g.L $\left.\mathrm{L}^{-1}\right)$, ágar $\left(6 \mathrm{~g} . \mathrm{L}^{-1}\right)$, água de coco (15\%), caseína hidrolisada (CH) (500 mg.L-1 $)$, AIA $(0$ e $14 \mu \mathrm{M}) ; \mathrm{AG}_{3}(0 \mathrm{e}$ $1,5 \mu \mathrm{M})$, Kin $(5 \mu \mathrm{M}), 2-\mathrm{iP}(12 \mu \mathrm{M})$; BAP $(4 \mu \mathrm{M})$. As culturas foram mantidas no escuro por 10 dias e transferidas para sala de crescimento sob regime de luz de 16 horas, temperatura de $25 \pm 2^{\circ} \mathrm{C} \mathrm{e} 40 \mu$ mol de radiação luminosa. A maior percentagem de germinação (75\%) foi obtida em meio MS suplementado com $\mathrm{CH}\left(500 \mathrm{mg} \cdot \mathrm{L}^{-1}\right), \mathrm{AIA}(14 \mu \mathrm{M}), \mathrm{AG}_{3}(1,5 \mu \mathrm{M})$ e Kin $(5 \mu \mathrm{M})$. Quando a Kin foi substituída por BAP $(4 \mu \mathrm{M})$, observou-se a formação de calo, sobre o qual se originaram gemas e brotações, cujos valores médios foram de 2,3 brotos por embrião e 12,3 gemas por brotação. Em relação ao comprimento das brotações, não houve diferença significativa entre os tratamentos. A maior percentagem de indução de calos ocorreu em meio de cultura suplementado com AIA, Kin e 2-iP. O meio de cultura MS/2 suplementado com $\mathrm{CH}$ e água de coco e isento de fitorreguladores, resultou em $25 \%$ de germinação. Já, o número de raízes foi maior no meio de cultura MS suplementado com AIA $(14 \mu \mathrm{M}), \mathrm{AG}_{3}(1,5 \mu \mathrm{M})$ e CH. O comprimento médio das raízes $(4,0 \mathrm{~cm})$ não foi afetado por nenhum tratamento em particular. Desta forma, esta técnica é uma alternativa eficiente ao uso de tratamentos de frio para a superação da dormência.
\end{abstract}

Termos para indexação: germinação in vitro, citocinina, $\mathrm{AG}_{3}$, caseína hidrolisada, água de coco.

\section{SUPPRESSION OF IN VITRO DORMANCY IN EMBRYOS OF ROOTSTOCK OF APPLE M9 (Malus pumilla Mill.)}

\begin{abstract}
The embryo dormancy in apple is a limiting factor in breeding programs with this species. Thus the present work was carried out in order to study the in vitro germination of M9 apple dormant embryos, originated from the Experimental Station of São Joaquim (EPAGRI/SC). The embryos, excised from mature seeds were inoculated in the basal culture medium MS supplemented with of sucrose $\left(30 \mathrm{~g} . \mathrm{L}^{-1}\right)$, coconut water $(15 \%)$, casein hydrolysate $(\mathrm{CH})\left(500 \mathrm{mg} . \mathrm{L}^{-1}\right)$, AIA $(0$ and $14 \mu \mathrm{M})$; $\mathrm{GA}_{3}(0$ and $1.5 \mu \mathrm{M})$; and three citokinins sources: $\left(\operatorname{Kin}(5 \mu \mathrm{M}) ; 2 \mathrm{PP}(12 \mu \mathrm{M})\right.$ and BAP $(4 \mu \mathrm{M})$. The culture medium was gellified with agar $\left(6 \mathrm{~g}^{-L^{-1}}\right)$. The cultures were maintained in the dark during 10 days, then transferred to growth room under 16 hours of light period, $25 \pm 2{ }^{\circ} \mathrm{C}$, temperature, and 19 $\mu \mathrm{E} \cdot \mathrm{m}^{-2} \cdot \mathrm{s}^{-1}$ of luminous radiation. The results showed that the highest value for embryo germination $(75 \%)$ was obtained in MS culture medium supplemented with $\mathrm{CH}$, AIA $(14 \mu \mathrm{M}), \mathrm{GA}_{3}(1.5 \mu \mathrm{M})$, and $\mathrm{Kin}(5 \mu \mathrm{M})$. When, in this treatment the Kin was replaced by BAP $(4$ $\mu \mathrm{M})$, it was observed the callus induction and the subsequent proliferation of buds and shoots, reaching values of 2.3 shoots/embryos and 12.3 buds/shoot. The length of shoots was $4 \mathrm{~cm}$, without statistical differences between the different treatments. The highest percentage of callus induction occurred in culture medium supplemented with AIA, Kin, and 2-iP. The culture medium MS half strength supplemented with $\mathrm{CH}$, coconut water and free of growth regulators resulted in values of $25 \%$ of germination. The root number was highest in the culture medium supplemented with AIA $(14 \mu \mathrm{M}), \mathrm{GA}_{3}(1.5 \mu \mathrm{M})$, and $\mathrm{CH}$. The average root length (4.0) was not affected by any particular treatment. Thus, this technique is an efficient alternative to the cool treatments for dormancy suppression.
\end{abstract}

Index terms: in vitro germination, citokinin, $\mathrm{GA}_{3}$, caseine, coconut water.

\section{INTRODUÇÃO}

O período juvenil na macieira pode ser significativamente reduzido, acelerando-se o crescimento das plântulas por enxertia em porta-enxertos anões e pela seleção para um período juvenil curto (Viser, 1970). Mesmo quando o período juvenil é encurtado por tais meios, ocorre um longo intervalo de tempo a partir do cruzamento até a germinação, tornando mais difícil e longo o programa de melhoramento genético para esta espécie (Roen, 1994).

Com o desenvolvimento de técnicas de cultivo in vitro, tornou-se possível, entre outras, obter-se plântulas viáveis em menos tempo. Isto pode ser obtido mediante o isolamento do embrião e seu cultivo asséptico em meios de cultura adequados que permitam a superação da dormência, o desenvolvimento embrionário e a germinação (Nakayama et al., 1974). Embora a

1 (Trabalho 248/2000). Recebido: 13/11/2000. Aceito para publicação: 18/01/2002.

2 Doutoranda em Fruticultura de Clima Temperado, FAEM/UFPEL, Pelotas, RS

3 Bolsista de Iniciação Científica, CCA, UFSC, Florianópolis, SC

4 Prof. Dr. Pós-Graduação em Recursos Genéticos, CCA/UFSC, Florianópolis, SC 
excisão de embriões a partir de sementes seja uma operação onerosa e demorada, plântulas originadas a partir do cultivo in vitro de embriões florescem mais precocemente, e podem servir como progenitores em futuros cruzamentos, reduzindo assim o ciclo de gerações (Roen, 1994).

As sementes da macieira apresentam dormência e necessitam de um ótimo de temperatura para sua superação. Normalmente, são necessários entre 75 a 90 dias em temperaturas de $2-6^{\circ} \mathrm{C}$ para que se inicie a germinação (Seeley e Damavandy, 1985). Estas condições podem ser substituídas pelo isolamento de embriões e pelos tratamentos com giberelinas, isoladamente ou em combinação com citocininas, e aplicados durante o tratamento a frio (Come e Durand, 1971) ou durante a germinação (Bulard, 1985; Durand et al., 1976).

Perino e Côme (1991) confirmam a existência, durante o processo de germinação de embriões de macieira, de duas principais fases: uma fase denominada sensu stricto e outra, chamada de fase de crescimento. A fase mais crucial é a da germinação sensu stricto, onde a transição para o crescimento da plântula é mediada por respostas na sensibilidade a fatores externos e a substâncias que possam ativar o metabolismo no embrião.

A superação da dormência da semente é acompanhada por pronunciadas mudanças no equilíbrio hormonal, envolvendo as giberelinas (Halinska et al., 1987), as auxinas (Côme, 1981) e as citocininas (Zhang e Lespinasse, 1991). As mudanças no equilíbrio hormonal podem resultar na influência exercida de um fitorregulador sobre níveis endógenos de outro, assim como em respostas morfogenéticas (Rudnicki et al., 1972). Além disto, as interações entre estes fitorreguladores afetam a superação da dormência e a subseqüente germinação das sementes (Dunlap e Morgan, 1977).

O meio mais utilizado para o cultivo de embriões é o MS (Murashige e Skoog, 1962) com algumas variações na sua suplementação com fitorreguladores. Contudo, as respostas dependem do genótipo da planta-matriz e do estágio de desenvolvimento do embrião. De uma forma geral, a taxa de germinação é tanto menor quanto mais jovem for o embrião (Bruck e Walker, 1985).

O objetivo deste trabalho foi estudar o efeito de diferentes combinações de fitorreguladores e outras substâncias orgânicas suplementadas ao meio de cultura MS, visando a superar a dormência de embriões e a promover a subseqüente germinação in vitro a partir de sementes maduras do porta-enxerto M9, oriundas da polinização aberta.

\section{MATERIAL E MÉTODOS}

Os frutos foram colhidos maduros, ao acaso, oriundos da polinização aberta do porta-enxerto M9 (Malus pumilla Mill.), em plantas-matrizes cultivadas na EPAGRI - São Joaquim (SC). O porta-enxerto M9, de hábito ananizante, é bastante utilizado em plantios de macieira em sistema de cultivo de alta densidade, por causa de sua precocidade e produtividade (Webster, 1997).

A etapa laboratorial foi conduzida no Laboratório de Fisiologia do Desenvolvimento e Genética Vegetal da Universidade Federal de Santa Catarina. Em câmara de fluxo laminar, os frutos foram submetidos a uma esterilização com etanol
$96^{0}$ por 10 minutos, seguida de hipoclorito de sódio a $2 \%$ por 20 minutos. As sementes foram removidas mediante corte transversal do fruto, sendo submetidas a uma desinfestação em álcool $70 \%$ por 30 segundos e hipoclorito de sódio $1,25 \%$ por $15 \mathrm{~min}$, seguidas de três lavagens com água esterilizada e autoclavada.

Os embriões foram então retirados das sementes e inoculados em tubos de ensaio, contendo $10 \mathrm{ml}$ de meio MS, acrescido de sacarose (30 g.L $\left.\mathrm{L}^{-1}\right)$, ágar, $\left(6\right.$ g.L $\left.\mathrm{L}^{-1}\right)$ (meio basal) e suplementado com os seguintes fitorreguladores e compostos orgânicos: A) ácido 3-indolacético (AIA) $(14 \mu \mathrm{M})$, ácido giberélico $\left(\mathrm{GA}_{3}\right)(1,5 \mu \mathrm{M})$ e caseína hidrolisada $(\mathrm{CH})\left(500 \mathrm{mg} . \mathrm{L}^{-1}\right)$; B) AIA $(14 \mu \mathrm{M}), \mathrm{GA}_{3}(1,5 \mu \mathrm{M})$ e CH$\left(500 \mathrm{mg} \cdot \mathrm{L}^{-1}\right)$ e cinetina (Kin) $(5 \mu \mathrm{M})$; C) AIA $(14 \mu \mathrm{M}), \mathrm{GA}_{3}(1,5 \mu \mathrm{M})$ e $\mathrm{CH}\left(500 \mathrm{mg} \cdot \mathrm{L}^{-1}\right)$ e isopenteniladenina (2iP) $(12 \mu \mathrm{M})$; D) AIA $(14 \mu \mathrm{M}), \mathrm{GA}_{3}(1,5 \mu \mathrm{M})$ e água de coco (AC) (15\%); E) AIA $(14 \mu \mathrm{M}), \mathrm{GA}_{3}(1,5 \mu \mathrm{M}), \mathrm{CH}$ (500 mg. $\left.\mathrm{L}^{-1}\right)$ e 6-benzilaminopurina (BAP) $\left.(4 \mu \mathrm{M}) ; \mathrm{F}\right) \mathrm{MS} / 2, \mathrm{CH}$ (500 mg.L $\left.\mathrm{L}^{-1}\right)$ e AC (15\%).

As culturas foram mantidas no escuro por 10 dias e, após este período, foram transferidas para sala de crescimento sob regime de 16 horas de luz e temperatura de $25 \pm 2^{\circ} \mathrm{C}$. Após 60 dias, os embriões foram coletados e avaliados quanto à percentagem de contaminação, oxidação e germinação, número e comprimento de brotações e de raízes, percentagem de calo formado nas raízes e cotilédones. Utilizou-se o delineamento experimental inteiramente ao acaso, com cinco embriões por parcela e cinco repetições por tratamento. Os dados foram submetidos à Análise de Variância e ao teste de separação de médias SNK, a 5\% de probabilidade.

\section{RESULTADOS E DISCUSSÃO}

A Análise da Variância apresentou efeitos significativos para o fator meio de cultura nas variáveis percentagem de germinação, percentagem de calos formados nas raízes e nos cotilédones, número de brotações, número de gemas e número de raízes (dados não mostrados).

A maior percentagem de germinação (75\%) foi obtida no tratamento $\mathrm{B}$, em meio de cultura basal suplementado com $\mathrm{CH}, \mathrm{AIA}(14 \mu \mathrm{M}), \mathrm{GA}_{3}(1,5 \mu \mathrm{M})$ e Kin $(5 \mu \mathrm{M})$. Entretanto, quando, neste meio basal, ocorreu a substituição da Kin pelo 2-iP $(2 \mu \mathrm{M})$, observaram-se os maiores valores médios para percentagem de indução de calos (tratamento C). Também nestes mesmos tratamentos, se observou uma maior percentagem de indução de calos originados nos cotilédones (Figura 1). Em relação a B, as taxas de germinação dos tratamentos $\mathrm{A}$ e $\mathrm{F}$ alcançaram valores relativos de $66,6 \%$ e os tratamentos $\mathrm{C}$ e $\mathrm{E}, 83,3 \%$.

Badizadegen e Carlson (1967) observaram que embriões maduros de macieira cultivados em meios de cultura suplementados com 25 ppm de BAP resultaram em $66 \%$ de germinação para cv. MacIntosh e 50\% para a cv. Wealthy. Já, Ivanicka e Mokra (1982) obtiveram $80 \%$ de germinação em embriões de Prunus avium cultivados em meio de cultura MS suplementado com AIA (5 mg.L $\left.\mathrm{L}^{-1}\right), \mathrm{AG}_{3}\left(0,5 \mathrm{mg} \cdot \mathrm{L}^{-1}\right)$ e de $\mathrm{CH}(500$ $\left.\mathrm{mg} \cdot \mathrm{L}^{-1}\right)$.

O tratamento A, cujo meio de cultura basal foi suplementado com AIA $(14 \mu \mathrm{M}), \mathrm{GA}_{3}(1,5 \mu \mathrm{M})$ e CH $\left(500 \mathrm{mg} \cdot \mathrm{L}^{-1}\right)$, induziu a formação de calos nas raízes. Tem sido sugerido que as auxinas podem, dependendo da concentração utilizada, estimular 

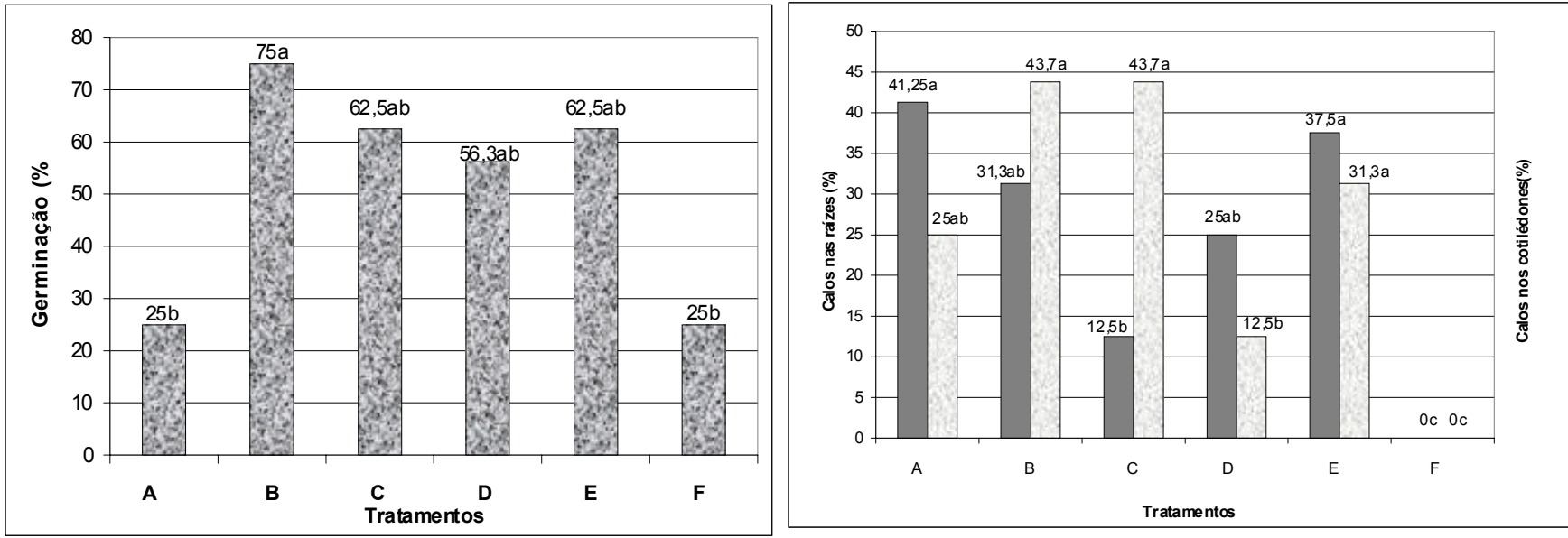

FIGURA 1 - Percentagem de germinação, de calos formados nas raízes e nos cotilédones do porta-enxerto de macieira M9, cultivados in vitro, em meio de cultura MS.CCA/UFSC, Florianópolis-SC, 2000.

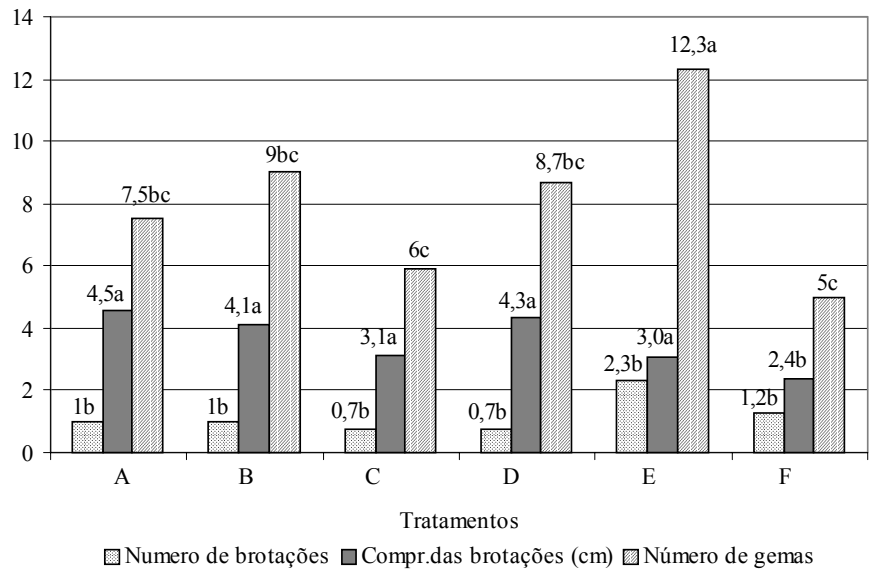

FIGURA 2 - Número e comprimento de brotações e de gemas produzidas em embriões do porta-enxerto de macieira M9, cultivados in vitro, em meio de cultura. CCA/UFSC, Florianópolis-SC, 2000.

a produção de calos (Grattapaglia e Machado, 1998). Este aspecto é corroborado pelo fato de que, no presente trabalho, os embriões cultivados no meio de cultura sem AIA não formaram calos. Apesar de alguns efeitos morfogenéticos inibitórios, as auxinas, em concentrações baixas, podem promover o crescimento do primórdio radicular, e o AIA, em baixas concentrações, pode estimular o desenvolvimento de embriões de algumas espécies (Rietsema et al., 1953; Krikorian, 1993).

O meio de cultura suplementado com AIA $(14 \mu \mathrm{M}), \mathrm{AG}_{3}$ $(1,5 \mu \mathrm{M})$ e $\mathrm{CH}$ e o meio de cultura $\mathrm{MS} / 2$ suplementado com $\mathrm{CH}$ e $\mathrm{AC}$ (tratamento $\mathrm{A} \mathrm{e} \mathrm{F}$, respectivamente) resultaram nas menores percentagens de germinação (25\%). Van Overbeck et al. (1941) obtiveram respostas positivas à $\mathrm{AC}$, adicionada ao meio de cultura, na germinação de embriões de Datura sp. Boase et al. (1993) observaram que a AC promoveu aumento no número de brotos e de gemas in vitro de Actinidia deliciosa. Tem sido sugerido que a AC, adicionada ao meio de cultura basal, forneça açúcares, vitaminas, aminoácidos, fitorreguladores e outros metabólitos essenciais às culturas (Caldas et al., 1998).

Não foram observadas diferenças em relação aos efeitos da $\mathrm{CH}$ quando comparados aos efeitos atribuídos aos meios de

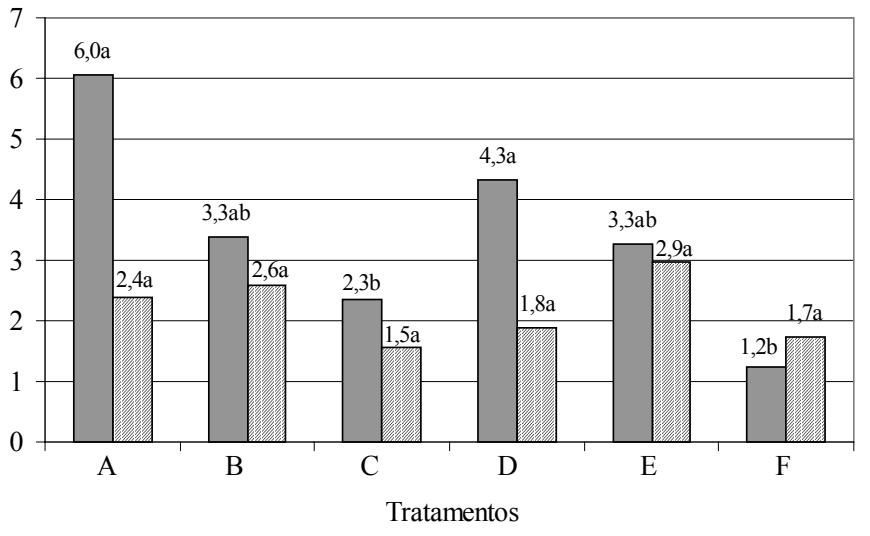

$\square$ Número de raízes 圈 Comprimento das raízes

FIGURA 3 - Número e comprimento de raízes em embriões do porta-enxerto de macieira M9, cultivados in vitro, em meio de cultura MS. CCA/UFSC, FlorianópolisSC, 2000.

cultura isentos deste composto. Contrariamente, Raganwamy (1961) reportou que a CH (400 mg. $\left.\mathrm{L}^{-1}\right)$ foi essencial para a germinação de embriões de Citrus microcarpa, $X$ Triticosecale (Bajaj, 1980), Oryza sativa (Shome e Bhaduri, 1982) e Prunus persica (Nakayama et al., 1974).

Em relação ao número de brotações e gemas produzidas, a melhor resposta foi observada com o meio de cultura basal suplementado com BAP $(4 \mu \mathrm{M})$ (tratamento E), o qual promoveu a neoformação de 2,3 brotos por embrião e 12,3 gemas por brotação (Figura 2). Quanto ao número de brotos, os outros tratamentos resultaram em valores inferiores, em torno de $30 \%$ do tratamento E. Já em relação ao número de gemas, os tratamentos $\mathrm{B}$ e D resultaram em valores de $70 \%$ do tratamento $\mathrm{E}$, e os tratamentos A, C e F, de $45 \%$.

Estes resultados podem ser atribuídos ao efeito citocinínico forte do BAP (Krikorian, 1993), em relação às outras citocininas (Kin e 2-iP) empregadas no presente trabalho. De acordo com Fiorino e Leva (1983) e Berardi et al. (1993), o BAP é a citocinina mais ativa e mais utilizada na multiplicação de brotações e de gemas em macieira e pereira.

Em relação ao comprimento das brotações, não houve 
diferença estatística significativa entre os tratamentos. Entretanto, foi observado maior valor no tratamento A, constituído pelo meio de cultura suplementado com AIA, $\mathrm{GA}_{3}$ e $\mathrm{CH}$. O menor valor foi observado no tratamento $\mathrm{F}$, constituído pelo meio de cultura MS/2 suplementado com $\mathrm{CH}$ e AC, apresentando $2,4 \mathrm{~cm}$ de comprimento nas brotações após 60 dias de cultivo in vitro (Figura 2).

$\mathrm{O}$ número de raízes foi maior nos meios de cultura suplementados com AIA, $\mathrm{AG}_{3}$ e isentos de citocininas (tratamentos $\mathrm{A}, \mathrm{E}$ e D). Já para o comprimento de raízes, não houve diferenças estatísticas significativas, porém os tratamentos A, B e E apresentaram mais de 2,0 cm de comprimento (Figura 3). A característica comprimento de raízes é importante para a aclimatização destas plântulas em viveiro.

Neste trabalho, pode-se verificar que a suplementação in vitro com os fitorreguladores $\mathrm{AG}_{3}$ AIA e diferentes fontes de citocininas foi determinante para a superação da dormência dos embriões do porta-enxerto M9. Segundo Hartmann et al. (1990), o $\mathrm{AG}_{3}$ é importante para a superação da dormência físiológica em embriões, estimulando a germinação. Entretanto, Bewley (1997) e Khan (1994) observaram que $\mathrm{o} \mathrm{AG}_{3}$ não parece estar envolvido no controle da dormência per se, mas tem importância vital na promoção e manutenção da germinação. $\mathrm{O} \mathrm{AG}_{3}$ é conhecido como um promotor da germinação em oposição à ação inibitória do $\mathrm{ABA}$, e em combinação com citocininas promove a superação da dormência promovida pelo ABA.

\section{CONCLUSÕES}

Em macieira, poucos trabalhos têm reportado sucesso no resgate, cultivo e germinação de embriões maduros em meios de cultura, suplementados ou não com fitorreguladores ou complexos naturais, como $\mathrm{AC} \mathrm{e} \mathrm{CH}$. No presente trabalho, foram alcançadas taxas expressivas de superação in vitro da dormência do porta-enxerto de macieira M9, por meio da técnica resgate de embriões. A suplementação do meio de cultura basal, com os fitorreguladores $\mathrm{AG}_{3}$, AIA, 2-iP, BAP e Kin e os complexos naturais $\mathrm{CH}$ e $\mathrm{AC}$, aumentou significativamente as taxas de sucesso na obtenção de plântulas, comparativamente aos meios isentos destes compostos. Estes resultados são relevantes porque demonstraram que esta técnica se constitui numa alternativa eficiente e rápida à superação da dormência de embriões de macieira comparativamente ao tratamento convencional a frio.

Os resultados indicam o potencial de uso desta biotecnologia, como técnica auxiliar efetiva nos programas de melhoramento genético de porta-enxertos de macieira, notadamente quando há a necessidade da utilização de embriões oriundos de cruzamentos.

\section{AGRADECIMENTOS}

Aos Pesquisadores da EPAGRI-São Joaquim/SC, pelo fornecimento dos frutos.

\section{REFERÊNCIAS BIBLIOGRÁFICAS}

BADIZADEGAN, M.; CARLSON, R.F. Effect of N6benzyladenine on seed germination and seedling growth of apple (Malus sylvestris Mill.). Proceedings American Society Horticultural Science, Geneva, v. 91, p.1-8, 1967.

BAJAJ, Y.P.S. Enhacement of the in vitro development of triticale embryos by the endosperm of Durum wheat. Cereal Reserch Communications., Hungria, v.8, p.359-364, 1980.

BERARDI, G.; INFANTE, R.; NERI, D. Micropropagation of Pyrus calleryana Dcn. From seedlings. Scientia Horticulturae, Amsterdam, v.53, n.1-2, p.157-165, 1993.

BEWLEY, J.D. Seed germination and dormancy. The Plant Cell, Rockville, v.9, p.1055-1066, 1997.

BOASE, M.R.; WRIGHT, S.; McLEAY, P.L. Coconut milk enhacement of axillary shoot growth in vitro of kiwifruit. New Zealand Journal of Crop and Horticultural Science, Wellington, v.21, n.2, p.171-176, 1993.

BULARD, C. Intervention by gibberellin and cytokinin in the release of apple embryos from dormancy: A appraisal. New Phytologyst, New York, v. 101, p.241-249, 1985.

CALDAS, L.S.; HARIDASAN, P.; FERREIRA, M.E. Meios nutritivos. In: TORRES, ${ }^{\mathrm{a} C}$.; CALDAS, L.S.; BUSO, J.A. Cultura de Tecidos e Transformação genética de Plantas, Brasília: 1998. p. $87-132$.

CÔME, D. Problems of embryonal dormancy as exemplified by apple embryo. Israel Journal of Botany, Jerusalem, v.29, p.1451456, 1981.

CÔME, D.; DURAND, M. Influence de l'acide gebbérellique sur la levée de dormance des embryons de pomier (Pirus malus L.) par le froid. Comptes Rendus de L'Academies des Science, Cedex, Série D, v.273, p.1937-1940, 1971.

DUNLAP, J.R.; MORGAN, P.W. Reversal of induced dormancy in lettuce by ethilene, kinetin and gibberellic acid. Plant Physiology, Bethesda, v.60, p.222-224, 1977.

DURAND, M. CÔME, D.; THÉVENOT, Factors liable to modify the action of gibberellic acid on the germination of more or less dormant apple embryos. Acta Universitatis Nicolai Copernici, Biol XVIII, v.37, p.59-66, 1976.

FIORINO, P.; LEVA, A.R. Propagation of apple cultivars. Acta Horticulturae, Leuven, v.131, p.95-99, 1983.

GRATTAPAGLIA, D.; MACHADO, M.A. Micropropagação. In: In: TORRES, ${ }^{a}$ C.; CALDAS, L.S.; BUSO, J.A. Cultura de Tecidos e Transformação genética de Plantas, Brasília Embrapa - SPI, 1998. Brasília, p.183-260, 1998. 
HALISKA, A.; SINSKA, I.; LEWAK, S.T. Embryonal dormancy in apple seeds in controlled by free and conjugated gibberellin levels in the embryonic axis and cotyledons. Physiologia Plantarum, Copenhagen, v.69, p.531-534, 1987.

HARTMANN, H.T.; KESTER, D.E.; DAVIES, F.T. Plant propagation principles and practices. Englewood Cliffs, Prentice Hall, 1990.

IVANICKA, J.; MOKRÁ, A. Development and cultivation of early-ripening cherry embryos. Biologia Bratislava, Bratislava, v.37, n.1, p.3-12, 1982.

KHAN, A.A. Induction of dormancy in nondormanct seedes. Journal of the American of Society for Horticultural Science, Alexandria, v.119, p.408-413, 1994.

KRIKORIAN, A . D. Medios de cultivo: generalidades, composición y preparación. In: ROCA, W.M.; MROGINSKI, L.A. Cultivo de tejidos en la agricultura, fundamentos y aplicaciones. Cali: CIAT, 1993.p.41-77

NAKAYAMA, F.; RACCA. R.W.; TORROBA, C.A Obtencion de plantulas in vitro com embriones imaturos de cultivares precoces de duraznero (Prunus persica (L.) Batsch.). Revista de la Facultad de Agronomía, La Plata, (3ª́p), v.1-2, p. 81-93, 1974.

NEIL, C.A; TOPOLENSKI, L.D. Hormonal regulation of growth and development of tomato embryos in vitro. Journal of the American Society for Horticultural Science, Alexandria, v. 110, n.6, p.869-873, 1985.

RAGANWAMY, N.S. Experimental studies on female reproductive strutures of Citrus microcarpa Bunge. Phytomorphology, New Delhi, v.11, p.109-127, 1961.

RIESTEMA, J.; SATINA, S.; BLAKESLEE, A.F. The effect of sucrose on the growth of Datura stramonium embryos in vitro. American Journal of Botany, Bronx, v.40, p.538-545, 1953.

ROEN, D. Prospects for shortening the breeding cycle of apple (Malus $x$ domestica Borkh.) using embryo culture I. Reducing the period of cold treatment by hormone application. Gartenbauwissenschaft, Stuttgart, v.59, n.2, p.49-53, 1994.

SEELEY, S. D. and H. DAMAVANDY. Response of seed of seven deciduos fruits to stratification temperatures and implications for modeling. Journal of the American Society for Horticultural Science, Alexandria, v.110, p.726-729 1985.

SHOME, A.; BHADURI, P.N. In vitro of immature embryos of rice Oryza sativa L. Indian Journal of Experimental Biology, New Delhi, v.20, p.184-186, 1982.

SINSKA, I. Interaction of ethephon with cytokinin and gibberellin during the removal of apple seed dormancy and germination of embryos. Plant Science, Pretoria, v.64, p.39-44, 1989.

VAN OVERBEEK, J.; CNKLIN, M.E.; BLAKESLEE, A.F. Factors in coconut milk essential for growth and development of very young Datura embryos. Science, Alexandria, v.94, p.350-351, 1941.

VISSER, T. The relation between growth, juvenile period, and fruiting of apple seedlings and its use to improve breeding efficiency. Euphytica, Wageningen, v.19, p293-302, 1970.

WEBSTER, A.D. A review of fruit tree rootstock research and development. Acta Horticulturae, Leuven, v.451, p.53-73, 1997.

ZHANG, Y.X.; LESPINASSE, Y. Removal of embryonic dormancy in apple (Malus $x$ domestica Borkh.) by 6-benzylaminopurine. Scientia Horticulturae, Amsterdam, v.46, p. 215-223, 1991. 